WellBeing International

WBI Studies Repository

$1-2015$

\title{
Fish Intelligence, Sentience and Ethics
}

Culum Brown

Macquarie University

Follow this and additional works at: https://www.wellbeingintlstudiesrepository.org/acwp_asie

Part of the Animal Studies Commons, Comparative Psychology Commons, and the Other Animal Sciences Commons

\section{Recommended Citation}

Brown, C. (2015). Fish intelligence, sentience and ethics. Animal cognition, 18(1), 1-17.

This material is brought to you for free and open access by WellBeing International. It has been accepted for inclusion by an authorized administrator of the WBI Studies Repository. For more information, please contact wbisr-info@wellbeingintl.org.

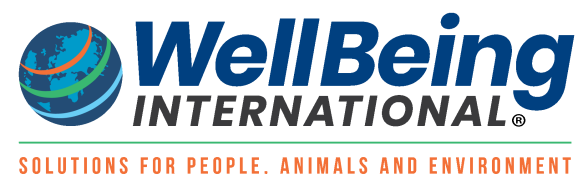

SOLUTIONS FOR PEOPLE, ANIMALS AND ENVIRONMENT 


\title{
Fish Intelligence, Sentience and Ethics
}

\author{
Culum Brown \\ Macquarie University
}

KEYWORDS

fish cognition, sentience, welfare, pain, intelligence, ethics

\begin{abstract}
Fish are one of the most highly utilised vertebrate taxa by humans; they are harvested from wild stocks as part of global fishing industries, grown under intensive aquaculture conditions, are the most common pet and are widely used for scientific research. But fish are seldom afforded the same level of compassion or welfare as warm-blooded vertebrates. Part of the problem is the large gap between people's perception of fish intelligence and the scientific reality. This is an important issue because public perception guides government policy. The perception of an animal's intelligence often drives our decision whether or not to include them in our moral circle. From a welfare perspective, most researchers would suggest that if an animal is sentient, then it can most likely suffer and should therefore be offered some form of formal protection. There has been a debate about fish welfare for decades which centres on the question of whether they are sentient or conscious. The implications for affording the same level of protection to fish as other vertebrates are great, not least because of fishing-related industries. Here, I review the current state of knowledge of fish cognition starting with their sensory perception and moving on to cognition. The review reveals that fish perception and cognitive abilities often match or exceed other vertebrates. A review of the evidence for pain perception strongly suggests that fish experience pain in a manner similar to the rest of the vertebrates. Although scientists cannot provide a definitive answer on the level of consciousness for any nonhuman vertebrate, the extensive evidence of fish behavioural and cognitive sophistication and pain perception suggests that best practice would be to lend fish the same level of protection as any other vertebrate.
\end{abstract}

\section{Introduction}

Most people rarely think about fish other than as food or as pets. However, fish are the most consumed animal in terms of numbers, the most numerous kind of pet, and are second only to mice in terms of the numbers used in scientific research (Huntingford et al. 2006; Iwama 2007; Sneddon 2013). There are more species of fish than all other vertebrates combined (ca 32,000 known species). Despite the fact that humans and fish interact on many levels and in greater numbers than mammals or birds, fish have not roused much public concern regarding their welfare. Perhaps the primary reason for this lack of consideration relates to the public perception of their level of intelligence and ultimately of whether they are conscious. All evidence suggests that fish are, in fact, far more intelligent than we give them credit. Recent reviews of fish cognition suggest fish show a rich array of sophisticated behaviours. For example, they have excellent long-term memories, develop complex traditions, show signs of Machiavellian 
intelligence, cooperate with and recognise one another and are even capable of tool use (Bshary et al. 2002; Brown et al. 2011a, b). Emerging evidence also suggests that, despite appearances, the fish brain is also more similar to our own than we previously thought. There is every reason to believe that they might also be conscious and thus capable of suffering.

The objective of this review is to bridge the gap between public perception of fish cognition and scientific reality with a view to informing the fish ethics/welfare debate. This is particularly pertinent given the general belief that welfare depends to a large degree on an animal's cognitive ability (Duncan and Petherick 1991; but see Dawkins 2001). A greater understanding of animal cognition will likely influence our view of animal welfare. I do not attempt to provide detailed reviews of fish perception and cognition as such work would require many volumes (see Brown et al. 2011a). I simply selectively refer to this work to illustrate the depth and scope of fish perception and cognitive abilities. Armed with this information, the public is in a far better position to make a judgement about fish consciousness and thus whether they should be afforded greater protection from cruelty. The review is largely restricted to bony fish (teleosts) since we know far too little about the cognitive abilities of sharks and rays (elasmobranchs). Moreover, we know next to nothing about the vast majority of fish species, and while it is hard to generalize between such diverse groups, we must assume that the capabilities that have been revealed in model taxa are likely to be exemplary of teleosts as a whole.

Here, I use the "feelings"-based approach to animal welfare and ethics which focuses on animal suffering (Appleby and Sandøe 2002). Suffering refers to prolonged periods of unpleasant mental states such as pain and fear. I acknowledge that the wild animals are frequently subjected to both pleasant and unpleasant experiences, but from a welfare and ethics perspective we wish to prevent extended period of suffering wherever possible. All of this ultimately depends on whether fish are capable of conscious, subjective experiences, and if we as scientists are capable of interpreting such experiences, both of which are generally controversial topics (Dawkins 1998).

\section{Science, public opinion and fish welfare}

The fact that we rarely come into contact with fish in their natural environment has implications with respect to our attitudes towards them. Fish live in an environment that we do not really understand and rarely visit, thus few of us ever see fish behaving naturally. The vast majority of people only ever see fish on their plate, and while lots of people keep fish as pets, fish seldom have the opportunity to express their natural behavioural patterns in captivity. This is in stark contrast with terrestrial animals such as dogs, cats and horses that have lived closely with people for tens of thousands of years and with whom we are very familiar. Whales, dolphins and seals, while living in the same aquatic media as fishes, are mammals, and thus, we seem far more capable of extending our circle of morality to include them. However, because fish are also phylogenetically distant to humans in comparisons with mammals, we find it very difficult to empathise with them. We cannot hear them vocalise, and they lack recognisable facial expressions both of which are primary cues for human empathy. Because we are not familiar with them, we do not notice behavioural signs indicative of poor welfare.

Our perception of an animal's intelligence largely defines the way we treat them when we interact with them (Kirkwood and Hubrecht 2001). Their level of intelligence defines whether or not we think they are sentient beings and thus worthy of inclusion in our "moral circle" (Lund et al. 2007). Science has the capacity to inform this debate and plays an important role in developing an accepted agreement about the standards in animal welfare. Science can also shift belief systems, albeit slowly. Changes in the belief system then trigger changes in legislation. For example, the UK's Animals (Scientific Procedures) Act 1986 prohibits experiments on vertebrates except under licence based on an assumption that all vertebrates have the capacity for conscious feelings. A ban on all great ape research in the EU was later 
declared (Directive 2010/63/EU) presumably because it is commonly believed that these animals have superior cognitive powers and thus a greater capacity for suffering. This perception that cognition and consciousness are related is interesting considering that consciousness may have arisen long before cognitive complexity (Dawkins 2001). Given the common poor perception of fish intelligence, it is hardly surprising that the ethical treatment of fishes lags far behind their vertebrate cousins.

The UK Cruelty to Cattle Act 1822 banned the improper treatment of cows and sheep and was one of the world's first attempt at animal welfare legislation. The 1835 Cruelty to Animals Act included dogs and explicitly outlawed bear baiting and cockfighting. This was later repealed by the Cruelty to Animal Act of 1876, which was perhaps the first to formally protect animals from pain and suffering during scientific research, and gave special protection to cats, dogs and horses. Subsequently, primates became the subject of great empathy, but our compassion has gradually spread to cover elephants, dolphins and so on to recently include other farm animals in an industrial setting (e.g. pigs, chickens). The recent push for protecting the welfare of farm animals is a good example of how public opinion has shifted and resulted in significant changes in legislation. The move to protect primates, elephants and dolphins has perhaps arisen from our greater understanding of the cognitive capacities of these animals; the result of over 50 years of intensive research. Such a sea change has yet to occur for fishes, and fish are still not afforded appropriate protection in most countries. This is interesting given that they are vertebrates and technically (though clearly not in practice) are afforded the same legal protection in many developed countries.

Why is legislation rarely applied to fishes? I suspect that there are two explanations. The first relates back to public perception. Until scientific findings relating to fish intelligence filter through to the public, and the public believe that fish are conscious beings capable of suffering, there will be a lack of political or social will to promote fish welfare. Secondly, and this is a far more practical issue, the ramifications for such animal welfare legislation, should it be applied to fishes, is perhaps too daunting to consider. Certainly, the fishing industry, including aquaculture and recreational angling, would have to drastically alter its approach. These interest groups are also powerful lobbyists, and the commercial value of these practices is significant. Indeed this explains why fish are not covered by the Animal Welfare Act in the USA. It is interesting to note, however, that the UK is starting to move in this direction with Aquatic Animal Health Regulations 2009 requiring fish farms to keep records on mortalities and stock movements. With limited resources for animal welfare and limited knowledge about fish cognition, welfare priorities often fall well short of protecting fish.

\section{Evolution and biological complexity}

Given the complexity of the environment in which many fish live (social and physical), it should not be surprising that fish have a high degree of behavioural plasticity and compare favourably to humans and other terrestrial vertebrates across a range of intelligence tests (Bshary et al. 2002; Brown et al. 2011a, b). Whether or not fish are worthy of human consideration, and thereby afforded some protection, is informed by scientific knowledge regarding their mental capacities. Once this information is at hand, we can have an informed debate about fish-human interactions and create moral guidelines to direct animal welfare legislation.

Sadly, the general poor perception of fish intelligence is not restricted to the broader public but it is also deeply imbedded in scientific dogma and can be traced back to the very beginnings of scientific investigation in the western world. The scientific study of animal brains and behavior (and by proxy intelligence) has been dogged by the deep rooted notion that the evolution of vertebrates follows a linear progression from inferior to superior forms, culminating in humans at the apex. This anthropocentric story tells us that along this path, we see increasing complexity and advances in brain and behaviour, leading to greater intelligence and behavioural plasticity at each evolutionary stage. Accordingly, the "primitive" 
vertebrates such as fishes are supposed to have simple brains with a few neural circuits that control elementary forms of behaviour. The more recent or "advanced" groups such as humans and other primates, so this discredited but still commonly believed theory argues, have evolved more complex brain circuits providing sophisticated and flexible cognitive capabilities including emotions, feelings and consciousness. Romanes' Animal Intelligence (1882) provides a classic example of this kind of thinking where he tries to show that animals become more advanced (humanlike) as we move up the evolutionary scale. More recent examples include Thorpe's Learning and Instinct in Animals (1956) and even Mcphail (1982) remains loyal to "the scale of nature" structure even as he explicitly rejects the idea of cognitive differentiation among vertebrates.

In 1859, Darwin published The Origin of Species, which totally revolutionised evolutionary biology. But despite Darwin's theoretical insights, the tiered and directed perspective of evolution continues to be taught at school 150 years later. In reality, evolution is a random rather than directed process. Rather than representing evolution as a linear or tiered progression of increasing complexity, we now view the vertebrates as a highly diverse radiation each with their own specialisations. Each group represents a more or less parallel line of evolution radiating from a common ancestor, and each species is specifically tuned to match the niche it occupies. In short, every species is unique. Following this reasoning, biological or cognitive complexity is not defined by how closely animals are related to humans but rather by the niche they occupy and the problems they commonly face during their everyday existence.

While there is no doubt that fishes are the most ancient vertebrates, they are only "primitive" in the sense that fish of some description have been on earth for in excess of 500 million years and that all other vertebrates evolved from some common fishlike ancestor around 360 million years ago. But fish have not been standing in an evolutionary backwater all that time, rather they have been evolving and adapting to new environments which has led to the massive diversity that we see today. There has been ample time for fishes to evolve complex and diverse behavioural patterns as well as the cognitive hardware that goes with it to match the diversity of ecological niches they occupy. Moreover, the vast majority of fish species on the planet are relatively new arrivals. While the Devonian period (410 million years ago) is often referred to as The Age of Fishes, most of the contemporary species are from the Percomorpha which showed a spate of massive speciation just 50 mya and reached peak diversity around 15 mya. To put that in perspective, the family Hominidae also evolved around the same time. Thus, most fish species are no more "primitive" than we are. And, despite apparent differences between fish and humans, evolution tends to be highly conservative; thus, many human traits are identical to or derived from our fishlike ancestors.

\section{Defining intelligence, consciousness and sentience}

Most animal ethics practitioners draw a line in the sand when it comes to which animals should be afforded protection from cruelty. For most people, this is whether or not the animal in sentient or conscious. Sentience is not an easy thing to define or measure, and the meaning is constantly debated by scientists and philosophers alike, but it might be summed up in an ethical context as the ability to experience pleasure and pain (i.e. subjective, perceptual experiences; Dawkins 1998; Appleby and Sandøe 2002). Consciousness is a far broader concept and includes sentience, intelligence and selfawareness. Consciousness might be broadly described as an awareness of internal and external stimuli, having a sense of self and some understanding of ones place in the world (Chandroo et al. 2004; Bekoff and Sherman 2004). When philosophers discuss consciousness, they are nearly always referring to higher-order consciousness (thinking about one's actions and thinking about thinking). Most people agree, however, that suffering is a conscious experience albeit at a low level of consciousness (phenomenal consciousness; Block 1991). Many have argued that since we cannot measure mental states, feelings or perceptual experiences, the science of animal welfare is on far safer ground if we 
measure subjective behavioural responses that imply consciousness (Dawkins 2001). Measures such as attention and perception, self-recognition, theory of mind and episodic memory are often the subject of experimental examination and thus may be used as experimental evidence for consciousness.

It is widely argued that an animal that displays a high degree of cognitive complexity (intelligence) is likely to be sentient (Kirkwood and Hubrecht 2001; Huntingford et al. 2006, but see Bekoff 2006 re-suffering). The rationale suggests that consciousness is an emergent property of advanced cognitive capacities and associated complex neural circuitry (Macphail 1998). Moreover, if we assume that animals are conscious, then understanding their cognitive capacities is likely to inform us about the sorts of stimuli that induce unpleasant feelings (Nicol 1996). For example, a limited capacity for memory would suggest that an animal is unlikely to make associations between certain events and negative stimuli or their consequences. This in turn has profound implications for welfare considerations. Cognition is well defined, and the definition is broadly accepted. Animal cognition is the process by which animals acquire, process, store and act on information gathered from the environment (Shettleworth 2010, p. 4). Some would suggest that intelligence is about learning from past experiences and applying this knowledge to solve novel problems, in other words intelligence is about behavioural flexibility (Roth and Dicke 2005). Most scientists would probably agree that holistic intelligence relies on underlying cognitive processes. Here, I will use intelligence as a synonym for cognitive complexity.

One of the common problems we face is trying to be objective when measuring intelligence. A common approach in comparative cognition is to examine the problem-solving skills of animals in novel contexts, typically in controlled laboratory conditions. Some animals, however, do not adjust well to captivity and captive-reared animals are commonly a poor exemplar of their wild cousins. Moreover, one must devise a test that is equally applicable to a wide range of animals, and the apparatus must be one with which the subjects are motivated to and can physically engage with (Shettleworth 2010, Chapter 1). To do anything to the contrary is to not provide a level playing field. Bitterman $(1965,1975)$ carried out a famous series of experiments comparing the cognitive performance of fish and a range of other vertebrates in laboratorybased studies. He made some attempt to design the various tasks with the ecology (and hence evolutionary background) of each animal in mind, but in doing so highlighted the problems of comparing the cognitive ability of such vastly different animals. Our understanding of fish behaviour is now considerably advanced and more appropriate tests have been applied to a wide range of species. The results suggest that Bitterman's early findings are certainly outdated. Some classic examples of suitable tasks for comparative cognition include spatial learning, classical and operant conditioning and reversal learning. The use of social learning is also commonly viewed as a sign of intelligence. Copying social role models is very common behaviour in children and can lead to rapid acquisition of novel skills. Moreover, social learning can lead to the development of cultural traditions. Social learning allows cumulative information gathering over multiple generations and explains many of the advances in human technology. For example, the modern motor car could never have been invented from scratch, but rather represents cumulative knowledge gained and applied over more than a hundred years. There are also forms of social intelligence, for example where individuals deliberately manipulate the behaviour of others by deception or reconciliation (i.e. Machiavellian intelligence). Indeed, the social intelligence hypothesis is often touted as an explanation for the evolution of the large primate brain (Whiten and Byrne 1997). Tool use is also often associated with intelligence, and among primates and birds seem to be associated with rapid problem-solving, innovation and large executive brain areas (Reader 2003). The development of tools is seen as the turning point in human evolution. An animal might also be considered intelligent if it can form categories and generalise, for example by partitioning objects into groups based on similarity or dissimilarity. Finally, the use of numbers and making calculations based on addition and subtraction is also considered a sign of intelligence (for a comprehensive review of comparative cognition, see Shettleworth 2010). Although these tasks are widely used for comparative studies, there is still an 
inherent difficulty of comparing results across taxa. While not all of these behaviours have been investigated in fishes, a great many of them have and are discussed at length below. In general, fish compare well to the rest of the vertebrates in most tasks (Bshary et al. 2002; Brown et al. 2011a, b).

One of the basic canons of comparative cognition is that one should never invoke higher-order explanations for behaviour if they might be explained by simpler ones (Morgan's Canon). While this is strictly applied by many who study comparative cognition in fish, it is often not meaningfully applied by those studying humans and primates. Heyes (1993, 1994), for example, points out that many of the higher cognitive skills claimed for primates, such as theory of mind, have never been rigorously proven; for a nice example of this, see Coussi-Korbel (1994). Thus, once more we see that comparative psychologists are not playing on an even field. Part of the explanation for this disparity is the fact that there are basically two camps in comparative cognition research. The first seeks to explain the evolution of human intelligence by examining our closest ancestors. The second looks for broader patterns or generalisations across all vertebrate taxa in relation to the correlation between environmental factors and the evolution of intelligence, typically by looking at specific areas of the brain and related behaviours (e.g. caching behaviour in birds and the hippocampus). It is reasonably simple to understand why the former seldom conform to Morgan's canon; if humans solve problems in this way, then it is reasonable to assume that our closest relatives might also. To ignore this possibility is to ignore the most basic rules of the evolutionary process; the difference between closely related species is one of degree not of kind. Thus, such higher-order cognitive process is often attributed to primates without rigorous testing, but this seldom occurs in fish because it would not be accepted by the scientific community due to an underlying assumption of simplicity rather than complexity.

\section{Fishes sensory perception}

The study of comparative cognition always begins with information acquisition, and thus, there is a strong underlying need to understand the sensory perception capabilities of the study animal. Part of this relates to avoiding anthropomorphism, for example by assuming that animals literally see the world as we do. However, it also relates to designing tests that are both appropriate and applicable to the study species. So in order to get inside an animal's head, to try to understand why it does what it does, one must first understand how it views the world around it. Fish occupy an incredible array of habitats, and there are a lot of species, so it is very difficult to generalise. Nevertheless, the environment in which a fish lives really shapes the senses it relies on. This theme will crop up repeatedly in what follows. Water differs from air in a wide range of biologically important ways, and it has ramifications for understanding the evolution of fish senses, behaviour and cognition.

\section{Vision}

Most fish have standard vertebrate eyes and those living in shallow water habitats, such as coral reefs, have the full spectrum of light available to them. Since the early experiments conducted by von Frisch (1913), we have known that most species are at least tetrachromatic which means they can differentiate between colours better than we can. The common goldfish for example has cones that absorb at 400, 450, 530 and $620 \mathrm{~nm}$ (Neumeyer 1982). Fishes' visual acuity (i.e. how clearly they see objects) is just as good as ours (Douglas and Hawryshyn 1990).

Work in cichlids, guppies and sticklebacks all show that ultraviolet (UV) is important for mate choice and species recognition. The detection of UV can also occur in some parts of the life cycle and then be reduced or lost entirely. Brown trout, for example, can see in the UV when they are young and occupy relatively shallow streams, but then lose this ability as they grow and occupy deeper waters (Deutschlander et al. 2001). There is some suggestion that some species of fish use UV as a discrete 
channel for communication since their predators are unable to see in this part of the visual spectrum (Siebeck et al. 2010). An equal array of fish can see polarised light, including damsel fish, cichlids, salmonids and goldfish (Kamermans and Hawryshyn 2011). In these species of fish, polarised light can be used for three primary purposes: (1) increased contrast when foraging on small prey such as zooplankton, (2) visual communication and (3) spatial orientation.

The fact that fish have such good vision means it can be difficult to present them with realistic stimuli using standard video equipment. Nevertheless, fish do respond to video playback. In fact, video playback is often a useful tool to break down various elements of complex cues (Rosenthal 1999). For example, female swordtails are attracted to the long swords that adorn the male caudal fin, but it is difficult to isolate the rest of the male's characteristics from the sword. Rosenthal and Evans (1998) showed manipulated video clips of the same male with a tail, without a tail but of equal total length and a dancing tail on its own to receptive females. Females were not interested in a dancing sword on its own and did not differentiate between males with and without tails. Thus, the sword tail most likely evolved as a cheap means for males to fake larger body sizes preferred by females.

Interestingly, fish are also known to fall for optical illusions which suggest that they not only take in visual information but complex processing also occur at the level of perceptual organisation (see Agrillo et al. 2013 for a review). For example, both goldfish and redtail splitfin perceive illusory contours in a manner similar to primates (Wyzisk and Neumeyer 2007; Sovrano and Bisazza 2008, 2009). Even sharks see optical illusions (Fuss et al. 2014). The fact that these fish species are highly divergent suggests that this ability is widespread in fish and vertebrates generally. Rather than seeing what is actually there, the vertebrate brain makes assumptions based on preconceptions which are likely based on a mix of prior experience and neural circuitry (Kandel et al. 2000). Thus, the fish brain, like the primate brain, seems to examine objects as a whole rather than paying attention to particular parts. If certain parts of an object are missing, the brain fills them in.

\section{Olfaction}

Smell (olfaction) and taste (gustation) in fishes work much in the same way as in humans. The chemosensory ability of most fishes is very highly developed, and they use this information for a wide variety of behaviours including feeding, predator recognition, mate choice and navigation. The smelling ability of sharks is about 10,000 times more sensitive than ours. Of the five primary gustatory categories, human identify and respond to (sweet, sour, salty, umami, and bitter), fish probably only respond to two of these (sour and bitter) in a biologically meaningful way (for a review see Hara 1994).

Because fish are submersed in water, there is no restriction as to the location of their taste buds. The variability in location and density of taste buds tells us a lot about the environment in which the fish lives and its feeding habits. Cyprinids, for example, may have as many as 300 taste buds per $\mathrm{mm}^{2}$, and density is associated with the fishes' feeding habits (Gomahr et al. 1992). Some classic examples serve to illustrate how important chemosensory abilities are to fishes include response to alarm substance, the use of the major histocompatibility complex $(\mathrm{MHC})$ for kinship and mate recognition, and imprinting on natal stream chemical cues in salmonid homing behaviour.

von Frisch (1941) discovered that minnows showed an innate fright response when one of their conspecifics was harmed. He named the mysterious chemical substance Schreckstoff (literally "fright stuff"), and we now know that this substance is held in special skin cells (club cells) in all ostariophysan fishes. The substance plays a crucial role in enabling naïve fish to recognise dangerous predators via classical conditioning. When a conspecific is hurt or killed by a predator, the alarm substance is released into the water resulting in anti-predator responses in the surrounding fish. When this occurs, fish are 
capable of pairing the appearance of a predator with an appropriate biological response (e.g. schooling or crypsis) (for a review, see Brown et al. 2011b). Recent evidence has shown that embryonic fish are capable of distinguishing between predators (Oulton et al. 2013) and that the pairing between alarm substances and predator cues during embryonic development enhances anti-predator behaviour once the eggs hatch (Nelson et al. 2013). This learning mechanism affords a high degree of behavioural plasticity which is necessary in a reasonably unpredictable, natural environment.

As we saw with the swordtail example above, female fish can be very choosey about whom to mate with. They can rely on a range of visual cues to determine the likely fitness of a male (such as size or colour) but they can also rely on chemical cues to figure out how genetically compatible males might be. Studies using sticklebacks have shown that females prefer to mate with males that have a different set of MHC alleles to themselves. MHC allelic diversity determines how effective an individual's immune system is likely to be. Female sticklebacks choose males that optimise rather than maximise MHC diversity in her resulting offspring (Milinski 2003). Studies conducted on humans have yielded similar results (Thornhill et al. 2003).

Last and not least, one of the greatest examples of animal migrations is the annual return of salmonids to their home streams. Many salmonids breed in cool upland rivers where their eggs are laid in gravel beds. As the eggs develop and hatch, the larvae and emerging young imprint on the chemical signature of their home stream. After spending various lengths of time in freshwater, they migrate to the ocean where they may spend several years growing to adulthood. Once mature, the fish return to their home streams by following chemical plumes from the river and matching it to the template laid down during the imprinting stage (Dittman and Quinn 1996).

\section{Hearing}

Anyone who has ever been diving will know that the underwater world is full of pops, creaks, snaps and crackles. As in terrestrial systems, there is a dawn and dusk chorus underwater associated with peaks in daily activity. Sound travels far greater distances (less attenuated) in water and at much greater speed (4.59 faster) than in the air. Moreover, air is readily compressed, so terrestrial vertebrates rely on membrane vibration to detect sound. In water, however, particle motion is the key to sound dispersal and detection. Thus, most aquatic animals rely on this vector to detect noise (see Popper and Lu 2000 for a review). This has a number of implications for the evolution of hearing in aquatic organisms.

Once again there is a large amount of hearing ability variability in teleost fishes, which largely depends on the environment the fish lives in, but scientists generally recognize hearing specialists and generalists. Specialists such as carp, catfishes, mormyrids (mildly electric fishes from Africa) detect a broad frequency range of the pressure component of sound, whereas generalists may only detect the particle motion component over low frequencies (e.g. perch and salmonids) (Amoser and Ladich 2005). Specialists generally come from relatively quiet environments (e.g. deep water, still lakes) whereas the reverse is true for generalists.

As well as having ears in a conventional sense (the inner ear is essentially conserved in all vertebrates), fishes also have a specialised system known as the lateral line which gathers vibration information from all over the body and sends it to the brain via the inner ear to be processed. This gives them a high degree of sensitivity, which is one of the ways fish in schools are so tightly coordinated. Some fish, including carp, use their swim bladder to detect sound and it this vibratory information which passes to the inner ear through a series of ear bones very similar to our own. Otiliths (ear bones) inside the fish's head also respond directly to vibration. 
One generally "asks" what a fish can hear by conducting behavioural experiments, but to date we have specific information about the hearing ability of fewer than 100 species. Some fishlike perch and salmon are capable of detecting infrasound $(<35 \mathrm{~Hz})$, whereas others such as herring can hear sound above 180 $\mathrm{kHz}$. Although historically there has been debate about whether fish can detect the location of a sound, recent evidence suggests that they can but they likely rely on different mechanisms than terrestrial vertebrates (Popper and Lu 2000). This certainly makes sense given the biological importance of localization and the manner in which sound travels in air and water.

Fish use sound in a similar way to terrestrial animals, include mate choice, navigation, territoriality and so on. They communicate to one another using sound in a variety of ways. It is thought that perhaps as many as $50 \%$ of fish species make some kind of meaningful noise for communication. Male cod and haddock for example have drumming muscles that vibrate on their swim bladder (Hawkins and Amorim 2000). Females choose males based on their drumming ability. Similarly, minnows shout at one another during aggressive interactions (Johnston and Johnson 2000). Many reef fish use the sound of the reef as a cue for navigation and settlement (Simpson et al. 2004).

Other senses

Unlike mammals, many fishes are also capable of detecting and creating electric currents in the water. Some fish such as the elephant nose fish and knife fish have developed a system similar to sonar where they send out bursts of electricity and detect changes in the electric field around them in order to find prey, navigate in their environment and communicate with their fellows. These fish are both electrogenic (they produce electricity) and electroreceptive (they detect and respond to electricity). Others, including sharks, rays and catfish, sense the tiny amounts of electricity produced when the neurons in their prey fire. Strongly electric fish, such as the electric eel, can produce enough current to stun their prey.

Many fishes can also detect and use the earth's magnetic field for both large- and small-scale navigation (magnetoception) as do many birds (Mouritsen and Ritz 2005). Sharks and other cartilaginous fishes have very highly developed magnetoception and possess a specialised organ (ampullae of Lorenzi) which detects changes in electric potential. This system is also involved in electroreceptivity as mentioned above. Despite the fact that the idea that fish could detect the earth's magnetic field and use it for longrange migration was first raised 120 years ago, the first experimental evidence did not appear until about 1980. There is still a considerable debate about how it works and what it is used for (for a review see Walker et al. 1997).

\section{Cerebral lateralization}

Not so long ago cerebral lateralisation was thought to be a unique human trait because it is so closely associated with higher-order cognitive processes in humans such as language production. But we now realise that brain hemisphere specialisation is widespread among vertebrates and perhaps even invertebrates (Rogers 2002; Vallortigara et al. 2011). Fish, like humans, prefer to use one side of their brain over the other when analysing particular sources of information (for a review see Bisazza and Brown 2011). However, the pattern of laterality often varies between species, between populations of the same species and even between individuals (Bisazza et al. 2000; Brown et al. 2004; Irving and Brown 2013). For example, Sarasins minnows look at a familiar individuals with their left eye and use their right eye to view unfamiliar individuals (Sovrano 2004). In this species, the right eye is commonly reserved for looking out for predators or other potentially threatening objects. This preference for using one eye or the other in social contexts also plays a role in the location rainbowfish prefer to adopt within a school (Bibost and Brown 2013). Individuals that prefer to use their left eye to view school mates tend to prefer positions on the right side of the school, while the reverse is true for those who prefer to view school mates with the 
right eye. In this way, a school might be comprised of an optimal number of fish with various degrees of laterality. Such a school would show faster responses to predators and prey on the periphery of the school while simultaneously rapidly responding to the behaviour of their school mates. This idea that laterality enhances multitasking is a common theory as to why laterality evolved in vertebrates particularly in social contexts (Vallortigara and Rogers 2005; Brown 2005). The study of laterality is yet another way to illustrate that fish can perform multiple complex tasks simultaneously and provides a non-invasive method to understand which hemisphere fish use when attending to various stimuli. Moreover, it is increasingly apparent that laterality varies with emotive content of stimuli and thus provides a method of studying emotional responses in fish (Brown and Bibost 2014a).

\section{Fish cognition}

So now we have a better understanding of how fish perceive the world. Clearly their senses are just as developed, and in some aspects better developed than our own. The question is what do they do with all the information they are taking in? In the following section, I will briefly outline types of cognitive abilities of which fish are capable. For comprehensive reviews on fish cognition, see Brown et al. (2011a, b) and Bshary et al. (2002).

\section{Learning and memory}

Perhaps the best place to begin is with fish memory. Anyone who has ever kept fish will know that they remember the hand that feeds them, the time of day and even the location where the food is likely to appear. Associating the latter two together is a phenomenon known as time-place learning. Klausewitz (1960), for example, reports a situation where a person hand fed fish in a lake. The fish gradually habituated to the feeder and readily accepted food when he was present. Even after a 6-month break the fish recognised him and fed within $3 \mathrm{~min}$ and refused to accept food from others. Time-place learning has been demonstrated in a number of fish species. A typical approach is to feed the fish at one end of an aquarium in the evening and the other end in the morning. Each day the location of the fish is recorded just prior to feeding. If the fish show anticipatory behaviour by congregating at the feeding end, then they have learnt the task. Poeciliids and galaxiids can learn this task in around two weeks (Brown unpublished data; Reebs 1999). Golden shiners and angel fish (Pterophyllum scalare) take 3-4 weeks (Reebs 1996; Gomez-Laplaza and Morgan 2005). By comparison, rats take about 19 days to learn this task (Means et al. 2000) and garden warblers learn slightly more complex tasks involving four locations and four time periods in just 11 days (Biebach et al. 1989).

It is quite common to see variability in learning ability between fish species and sometimes within species, particularly when fish are collected from different locations. Some of this variability is due to genetics (as a result of natural selection operating in differing environments), while some is due to the varying experiences fishes have during ontogeny. Both mechanisms operate to shape behaviour to match the prevailing environmental conditions. Typically, one finds that the learning ability, and behaviour generally, is shaped to suit the environment in which the fish live. We have examined the effects of rearing environment on learning using classical or Pavlovian conditioning. In Pavlovian conditioning, an animal effectively learns that one previously meaningless stimulus (e.g. a bell) is associated with or predicts a biologically important event (e.g. the arrival of food). This is a fundamental form of learning for most animals and was famously shown in Pavlov's dogs. In our experiments, fish had to learn that when a light was turned on food would shortly be delivered down a feeding tube. Wild rainbowfish showed rapid learning over 7 days (14 trials) and while a captive-reared population was initially slower to learn, they eventually caught up (Brown and Bibost 2014b). By comparison, rats take around 40 trials to learn an association between a tone and food (Bouton and Peck 1989). Pavlov's dogs learned the association 
between a novel odour and the administration of acid in the mouth in 20 trials, whereas in the classically cited study, a buzzer predicted the arrival of food "after a single combination" (Pavlov 1927, p. 27).

Spatial learning has been widely studied in fishes (for a review see Odling-Smee and Braithwaite 2003) and is for the most part comparable to any other vertebrates. For example, fish, birds, monkeys and humans can use basic geometry to recall the location of an object when in an oblong-shaped room (see Cheng and Newcombe 2005 for a review). If one of the walls is painted and thus can act as a salient cue, then adult humans will go to the correct location, but toddlers still rely on geometry (Hermer and Spelke 1994). In fact children cannot use featural cues until they are about 6 years old. In fishes trained with both features and geometric cues, fish can use both but rely on geometry once the features are removed, thus features do not overshadow geometry during the learning process (Sovrano et al. 2002, 2003; Vargas et al. 2004). Thus, the fishes' use of geometric cues is very similar to birds and rats and exceeds that of toddlers. One classic example of complex spatial learning in fish is exhibited by rock-pool dwelling gobies. A number of studies have shown that these small fish can also return to their home pool even after being displaced by $30 \mathrm{~m}$ (e.g. White and Brown 2013). Moreover, when disturbed, these gobies can leap into neighbouring rock pools (Aronson 1956). Even after being removed from their home pools for 40 days, the fish could still remember the location of surrounding pools. This astonishing ability makes use of a cognitive map that is built-up during the high tide when the fish are free to roam over the rock platform and which can obviously be maintained for extended periods of time in the absence of reinforcement. Thus, gobies and a range of other species have impressive long-term memories. The use of cognitive maps is a well-known concept in human navigation, but the term was first coined by Tolman (1948) to describe aspects of navigation in rats. It is now known that this sophisticated mental representation of the spatial relationships between environmental features is widespread in animal navigation (Collett and Graham 2004). Clark's nutcrackers are often considered to be the animal champions of long-term spatial memory and can retrieve cached food hordes at least 285 days after they were stashed but a fair degree of forgetting starts to set in after 183 days (Balda and Kamil 1992).

Animals often form long-term memories of negative experiences. For example when dogs are trained to avoid an electric shock, they maintain the avoidance behavior for up to 650 trials after the shock has been removed (Solomon and Wynne 1954). Fish can also learn to avoid aversive stimuli rapidly and retain the information for extensive periods. Fish can show one trial learning, for example pike that have been hooked often show hook shyness for over a year (Beukemaj 1970). Similarly, rainbowfish taught to swim through a hole in a net that travelled down the length of their aquarium took just five runs to figure out the location of the escape route. When tested almost a year later, they still recalled how to escape the net even though they had not seen the net in the intervening period (Brown 2001). This is remarkable for a fish that only lives for 2 years in the wild. Moreover, the more fish present in the group the faster they learn (Brown and Warburton 1999).

\section{Social learning and traditions}

There are widespread examples of social learning in animals. Perhaps the most celebrated is the unique use of tools among various populations of chimpanzees (Yamamoto et al. 2013). Social learning occurs when information passes from one individual to another by observation or interaction. This can lead to a transfer of information through generations (vertical transmission) resulting in cultural traditions. In the UK, blue and great tits learned how to open the lids on milk bottles to access the cream on top and the behaviour rapidly spread across the country via social learning (Fisher and Hinde 1949). Over the years my colleagues and I have conducted a large number of experiments examining social learning in fishes (see Brown and Laland 2011 for a review). For example, we showed that hatchery-reared salmon could be taught to recognize novel live prey by pairing them with fish that already recognised the prey. The naïve observers not only learn to eat the new food but they can also learn where to forage for it (Brown 
and Laland 2002a). We have also trained guppies to use particular routes in order to locate a foraging patch. In this instance, a school of fish (demonstrators) were trained to swim through a random door. Gradually one of the demonstrators was removed from the group and replaced with a naïve fish (observers). This continued until all the original demonstrators had been removed and the shoals still remained faithful to the original foraging route (Laland and Williams 1997). In some contexts, however, the tradition can break down in the absence of demonstrators (Brown and Laland 2002b), and this can lead to rapid loss of social traditions.

Social traditions are likely to be particularly strong in long-lived species and are thought to be responsible for the migration routes of several species of fish, including cod (Fernö et al. 2011). It has been postulated that the recent shifts in cod spawning grounds is the result of the systematic removal of older, knowledgeable individuals by commercial fishing (Fernö et al. 2011). Multiple experiments have shown us how this might work in practice. During the day, French grunts are found hiding among sea urchins where they are protected from predation by the urchin spines. Shortly after sunset, they migrate to feeding patches often associated with seagrass beds. The path they use between the resting and foraging locations is highly temporally stable. Helfman and Schultz (1984) transplanted fish between schools and observed what path the transplanted fish took on their sunset foraging run. Those individuals that were transplanted into schools where some of the original school remained followed the rest of the group (the "natives") to their traditional foraging ground. Those that were transplanted to new locations, where the original school had been removed, moved off in a heading similar to that they would have used if they were still at their home location. Obviously, the latter failed to find a foraging patch. Thus, it is quite apparent that fishes are capable of developing cultural traditions that are similar to some of those seen in birds and primates.

\section{Individual and kin recognition}

Social groups of animals are seldom made up of a random selection of individuals, and this is also the case with fish. Usually fish form relatively stable groups and become familiar with the individuals within that group. Similarly horses and dogs not only recognise individuals of their own species (Bonanni et al. 2011) but are capable of recognizing individual humans based on a number of different cues (Proops and McComb 2012) (recall the early example in fish). In humans, this capacity for individual recognition develops between 6 and 10 months of age (Fagan and Singer 1983). Guppies can remember the identities of up to 15 individuals with little difficulty (Griffiths and Magurran 1997). In relatively small shoals, familiarity takes about 12 days to develop and may be maintained even after 5 weeks of isolation (Bhat and Magurran 2006). When given a choice, fish will prefer to shoal with familiar rather than unfamiliar individuals (Magurran et al. 1994). Remembering who's who is important as it enables one to predict how each individual is going to behave in any given situation. Shoals comprised of familiar individuals, for example, and are better at avoiding predators than groups comprised of complete strangers (Chivers et al. 1995). Social learning is also enhanced in groups of familiar fish (Lachlan et al. 1998), and territorial cichlids show lower levels of aggression towards familiar than unfamiliar neighbours (dear enemy effect; Frostman and Sherman 2004). However, after many generations in captivity, fish may lose this preference for familiarity (Kydd and Brown 2009) which will have follow-on consequences for a range of social behaviours. Fish may also be able to recognise kin using both visual and chemical information (Arnold 2000; Gerlach et al. 2008), but in many cases this appears to be facilitated through familiarity mechanisms (Frommen et al. 2007).

\section{Self-recognition}

Many have argued that to be conscious animals must be capable of recognising the self. The typical test employed in this context is the mirror self-recognition test (MSR: Parker et al. 1994). In the classic 
example, a chimp has a small sticky dot attached to its forehead and then is given access to a mirror. In some cases, the chimp uses the mirror to study its reflection and then removes the dot from its forehead (as opposed to trying to remove the dot from the mirror; Gallup 1970). This suggests that the animal understands that it is looking at a reflection of itself and not an unknown conspecific. Most vertebrates, however, fail this test and the ability to recognise a mirror image of oneself seems to be largely limited to humans, great apes and dolphins (Reiss and Marino 2001). A typical response towards a mirror image by most animals is fear or aggression towards the unknown conspecific. Such responses are commonly observed in fishes. Great debate continues about whether or not the MSR tells us anything about an animal's ability to have more abstract levels of self-awareness. However, it may be argued that selfrecognition may not necessarily occur through solely through vision, and in many cases, olfactory recognition is perhaps more appropriate. This is certainly the case in fishes. Fish seldom (if ever) see their reflection so they are unlikely to have evolved visual self-recognition, but chemical cues play a very important role in aquatic ecosystems. There is compelling evidence that fish are capable of selfrecognition using chemical cues. Male cichlids, for example, preferred their own odour to those from unrelated males or brothers (Thünken et al. 2009).

\section{Social intelligence: cooperation and reconciliation}

Some have argued that the stable social groups one observes in primates have led to an increase in cognition over evolutionary time as members of the group attempt to outsmart one another to gain access to mating opportunities (Whiten and Byrne 1997). Submissive behaviours such as appeasement by lowranking individuals might be one method to manipulate higher-ranked individuals. Similar observations have been made in cichlid groups which also exist in extended family groups with a number of helpers (Taborsky 1984) as well as in anemonefish (Fricke 1974). Moreover, Siamese fighting fish are able to judge their position in a hierarchy by watching third parties interact with one another, a process known as eavesdropping (Oliveira et al. 1998). Female guppies can use the same method to judge male quality and may switch their prior mate choice decision based on this information (Dugatkin and Godin 1992). Similar sorts of behaviour are probably common in social groups where social hierarchies exist (e.g. chickens, Hogue et al. 1996; macaques, Silk 1999).

Living in complex social groups thus requires a whole new set of cognitive capacities to keep track of social relationships. Social intelligence has been mostly studied in primates (Byrne and Whiten 1989), but studies with dogs show that they are also highly socially skilful. Indeed there is evidence that dogs are better at reading social cues from humans than any primate, a skill which likely occurred early in the domestication process and co-opted the very well-developed social skills ordinarily reserved for socializing with pack members (Miklósi et al. 2004). This example serves to illustrate how important the environment is to shaping cognition and has little to do with how closely related animals are to humans.

Most fish live in social groups for most of their lives, and it should come as no surprise that they also display all sorts of behaviours that are indicative of social intelligence (Bshary et al. 2014). Fish often provide the best examples of cooperation in the animal kingdom (e.g. Shettleworth 2010, chapter 12). For example, fish tend to cooperate with one another when they are doing dangerous deeds like inspecting predators. If a pair of fish inspects a predator, they glide back and forth as they advance towards the predator each taking it in turn to lead. If a partner should defect or cheat in any way, perhaps by hanging back, the other fish will refuse to cooperate with that individual on future encounters (Milinski 1990). This shows that the fish not only recall the identity of the defector but they also assign a social tag to them and punish them on future encounters.

Perhaps the best known example of cooperation between fishes is that of the cleaner wrasse and its clients (see a review by Bshary 2011). Cleaner wrasse occupy cleaning stations on coral outcrops and 
remove parasites and dead skin from the surface of client fish. They have a large number of regular customers, and they recognise them all individually. The clients present themselves and perform a "clean me" stance which signals to the cleaner that they require a good service. Of course there are many stations a client can potentially visit so it is very important that the cleaner does a good job to keep up its reputation. If the cleaner should accidentally bite the client, then the client will rapidly swim away. But the cleaner has a mode of reconciliation; they chase after the distraught client and give them a back rub, thus enticing them to come again (Bshary and Wurth 2001). Cleaner fish can be selective about who they serve and they appear to classify their clients according to their residential status (local or transient) and their foraging tendencies (predator or nonpredator). If there are a number of clients waiting to be serviced, cleaner fish will prioritise transients, knowing that the locals have nowhere else to go (Tebbich et al. 2002). Cleaners are also partial to cheating and occasionally they nip the skin of clients to obtain a cheap meal. It is perhaps not surprising that they are far less inclined to perform this behaviour if the client is a predator. Thus, the cleaner wrasse not only recognise individual fish, but can also categorise different fish species based on their predatory tendencies. This ability to generalise is widespread in fishes. To date, however, categorisation based on "sameness", another classic sign of intelligence in animals, has not been formally tested in fishes.

Another fascinating example of cooperation in fish occurs between groupers and moray eels. In this case, the grouper approaches the moray eel and signals its intention to go hunting. In response, the eel emerges from its cavity and follows the grouper to the proposed hunting site. Upon arrival, the eel fossicks among the coral while the grouper cruises over the surface. Any fish that are scared by the eel are eaten by the grouper and vice versa. In this way, the foraging efficiency of both fish is greatly enhanced (Bshary et al. 2006). Cooperation in general is rare (Stevens et al. 2005) but cooperation between species like this is extremely rare and is reminiscent of the relationship between working dogs and humans.

\section{Building and tool use}

Some have argued that nest building is a precursor or even equivalent to tool use (Hansell and Ruxton 2008) as it involves complex manipulation of external objects. Moreover, nest building is often associated with parental care which is widespread among cichlids and gobies. What is not clear is the extent to which building involves cognition as many nest building behaviours appear to have strong innate underpinnings. Nevertheless, building is reasonably rare among vertebrates other than birds, although of course beavers are a key exception. It is worth keeping in mind that there are more species of fish builders than there are mammal species. At least 9,000 species of fish build a nest of some sort, either for laying eggs, or for shelter from predators. The nests vary tremendously in the materials used and their ultimate shape and function. Male gouramis build nests out of bubbles in which they entice females to lay their eggs. Various species of wrasse produce mucus cocoons which protect them from predators and parasites while they sleep (Grutter et al. 2011). The cutlips minnow collects around 300 identical pebbles and builds a mound $35 \mathrm{~cm}$ wide and $10 \mathrm{~cm}$ high, and tilefish make coral mounds up to $1 \mathrm{~m}$ high. The jawfish gathers together small rocks from the sand floor to build a wall in front of its burrow. These fishy masons search meticulously for rocks that fit together like a puzzle and leave a hole just big enough for it to slip through. Perhaps the most impressive builder is the rockmover wrasse. Each night it gathers up large bits of coral to make a house, in which it spends the night sleeping and abandons the next morning. Unlike the numerous studies of bird nest building behaviour, there have been very few relating to building behaviour in fish other than sticklebacks (Östlund-Nilsson and Holmlund 2003).

Not so long ago, tool use was one in a long list of skills that was supposed to be unique to humans; the theory was that tool use required an order of cognitive sophistication that no other species could match and is often cited as a key moment in our evolutionary history. Most famously Jane Goodall showed that 
primates and a number of other vertebrates also use tools (reviewed in van Lawick-Goodall 1970), although tool use in macaques had been identified much earlier (Carpenter 1887). Since then it has been revealed that all sorts of animals use tools and fish are no exception (for reviews see Seed and Byrne 2010; Brown 2012). Primates are still the main players, but tool use is also reasonably common in birds, particularly corvids, where New Caledonian crows are the star tool users (Hunt 1996). Among fishes, a number of species of wrasse use rocks to crush sea urchins so as to access the meat inside. Wrasse also commonly use anvils to break open shellfish (Jones et al. 2011). An examination of tool use in the wrasse family reveals that tool use has either evolved multiple times or is a common behaviour (Brown 2012). Interestingly, wrasse also have a larger than expected brain size, a theme that is also apparent in both tool-using birds and primates (Lefebvre et al. 2002; Reader and Laland 2002). Other examples of tool use in fish include cichlids and catfish which often glue their eggs to leaves and small rocks and then carry them around when their nest is threatened. Numerous fish, most notably the archerfish, squirt water from their mouths in order to dislodge prey items. Archerfish are perhaps the most well-studied group, and there is good evidence that they learn to compensate for the refraction as light passes from water to air (Dill 1977).

\section{Numerical competency}

The ability to conduct quantitative analyses is a fundamental ability in humans. For a long time, it was thought that humans were the only species capable of counting, but recent evidence is emerging that perhaps other species can also do this. Six-month-old infants can discriminate among small collections of objects (Antell and Keating 1983). Both five-month-old infants and monkeys can perform simple arithmetic with small numbers (Wynn 1992; Sulkowski and Hauser 2001). Similarly, young chickens are capable of simple arithmetic (Rugani et al. 2009). In humans, there appears to be two different systems for extracting numerical information that operate over different ends of the numerical spectrum (Trick and Pylyshyn 1994) although this is still controversial. The first is a system for estimating large quantities, referred to as the analogue magnitude system (Nieder and Dehaene 2009). It has no upper limits but is subject to Weber's law as it relates to the ability to differentiate between two quantities. When the ratio is small (i.e. there is small relative difference between quantities), it is hard to distinguish between them, but as the ratio increases (large relative difference) it becomes increasingly simple to differentiate between them. Such a system is important for making rapid choices regarding quantities. For example, if you had to choose between fighting 20 men or 10 men in a battle, you would rapidly head towards the fight with the best odds. The second system is basically an object-tracking system that allows us to follow individual objects (Whalen et al. 1999). This system is highly accurate but is limited in that we can usually only keep track of four elements at any one time. It allows us to instantly report how many objects we can see without having to count them in series. Dogs, for example, can spontaneously assess large magnitudes based on noise, and when in small groups use as object-tracking system when choosing to attack if their group outnumbers the invading group by 1 individual (i.e. 2v1, 3v2 or 4v3; Bonanni et al. 2011). Similar observations have been made in lions and monkeys (McComb et al. 1994; Kitchen 2004). Recent research has shown that guppies use the same methods of quantitative analysis as humans (Agrillo et al. 2012).

Examining counting ability in fishes is relatively simple and it makes use of the fact that many species school. The fundamental principal of schooling is that there is safety in numbers, so the bigger the group the safer you are. Thus, one can present fish with schools of differing sizes (and ratios) and their choice of schools tells us about their ability to differentiate between the two groups. Using this technique, we have learned that angel fish, for example, use both numerical systems to keep track of quantities (Gómez-Laplaza and Gerlai 2011a, b). When using the analogue magnitude system, angel fish could discriminate between large shoals when the ratio was just below 2:1. When choosing between small 
shoals fish could reliably chose 4 versus 1, 3 versus 1, 2 versus 1 and 3 versus 2 individuals, but could not choose between 4 versus 3, 5 versus 4 and 6 versus 5 . In contrast, both guppies and humans can differentiate 3 versus 4 just as easily as 1 versus 4 (Agrillo et al. 2012). Thus, there appears to be some small variability between fish species, but this likely depends on their schooling tendencies. There are some problems associated with these methods in that it is not entirely clear what cues the fish is using when choosing a school. For example, it might make a judgement on the overall amount of movement or the total area of fish. However, many of these issues can overcome by training the fish to respond to inanimate objects in which surface area and so on can be controlled.

\section{Fish pain perception and consciousness}

One of the more controversial questions in fish biology, and animal ethics generally, is whether fishes feel pain. It is worth stating from the very outset that there is absolutely no doubt that fish have all the hardware associated with pain perception (nociception) and that the application of analgesics reduces the symptoms (Sneddon 2003). Indeed if one examines the pain receptors in fish you would find remarkable resemblance to those in humans. The pain receptors in all vertebrates are conserved and derived from an early fishlike ancestor. Although the A-delta and C-fibre ratios differ somewhat, many of the fish A-delta fibres have the same characteristics as mammalian $\mathrm{C}$-fibres. So the only controversial question at the moment is how do fish respond to pain in a cognitive sense?

Rose et al. (2014) suggests that pain is an entirely emotional experience completely separated from the detection of painful stimuli (nociception). I suggest, however, that it is unreasonable to separate the physical detection of pain from the emotional or cognitive response to it since they are so clearly part of an integrated system that has evolved to reduce the chances of injury (Rollin 1989; Broom 2001). Thus, pain perception and processing of nociception stimuli clearly go hand in hand to maximize an animal's chances of survival. As Dawkins (2001) suggests, consciousness is a Darwinian adaptation and thus clearly provides animals with some advantage. Even the simplest emotional response to pain, fear, is widespread among vertebrates, and rightly so given that the primary outcome of this integrated system is to protect the animal from future harm. Thus, a basic response to pain is to avoid making contact with noxious stimuli in future. Fear-based conditioning is one of the foundations of comparative psychology (Skinner 1938). Moreover, the study of predator avoidance behaviour is arguably the most common research topic in modern behavioural ecology. Fish rapidly learn to associate certain objects, smells and contexts with potential harm and avoid such things in future (for a reviews of anti-predator behaviour in fishes see Kelley and Magurran 2003; Kelley and Brown 2011).

One of the more interesting forms of evidence that fish respond to pain in a cognitive sense is the fact that pain appears to distract fish and prevents them from carrying out other tasks or paying attention to external stimuli. When in pain, fish suffer from attention deficits. For example, a fish that has been injected with acetic acid loses fear of novel objects (neophobia) presumably because the cognitive experience of pain is dominant over or overshadows other processes (Sneddon et al. 2003). Similarly, the anti-predator responses of rainbow trout are disrupted and dominant fish become less aggressive if they are suffering pain (Ashley et al. 2009). It is perhaps not surprising given the diversity of fish behaviour that behavioural indicators of pain vary from species to species (Reilly et al. 2008). Fish are also willing to pay a cost to access pain relief (Sneddon et al. unpublished data).

There are effectively two opposing lines of arguments regarding emotional/cognitive response to pain. The first proposed by Rose (2002); Rose et al. (2014) suggests that fish do not have the cognitive complexity (or hardware) to respond to pain in an emotional sense. The argument is based on the fact that fish lack a neocortex and are thus not capable of consciousness and therefore do not respond to pain as humans do. The second argument favoured by Sneddon, Braithwaite, Huntingford, Chandaroo and 
others suggests that fish are in fact highly cognitive beings and show all the signs of responding to pain in a similar way that we do. They point to experimental evidence that suggests that fish show fear and other behavioural responses to pain that are not dissimilar to our own (Sneddon 2003, Braithwaite and Huntingford 2004; Chandroo et al. 2004). All of the science discussed in this paper offers strong evidence of fish as cognitive beings and most likely sentient, a fact Rose must deny in order to reach his conclusion. More to the point, however, it would be impossible for fish to survive as the cognitively and behaviourally complex animals they are without a capacity to feel pain. Feeling pain and responding appropriately (e.g. by avoidance) is clearly critical to survival and may even precede the evolution of higher-order cognitive processing (Dawkins 2001).

Despite the fact that Rose (2002) is strongly critical of anthropomorphism, his central argument is both anthropocentric and anthropomorphic: fish lack a humanlike neocortex and thus do not respond to pain in a meaningful conscious sense. In fact this would rule out pain perception in most vertebrates (e.g. most mammals, all birds, reptiles and fish). But this argument is contingent on Rose's erroneous belief that the neocortex is the centre of consciousness in humans and that fish lack any comparable structure. On the first point, recent analysis of the human neocortex has revealed that it has not undergone any special, radical evolution in humans, and there is no reason to suspect it is any more involved in consciousness than any other part of the human brain (Barton and Venditti 2013 and references therein). As Damasio (1999) points out, core consciousness in humans depends critically on the activity of a great many phylogenetically ancient brain areas as well. Modern approaches to neuropsychology tend to look at consciousness as an emergent property of a highly complex neural network that cannot be pinned to any particular location or structure. Even the "dynamic core hypothesis" of consciousness specifically states that the location of the core is not found any particular location within the brain, but rather depends on neuronal functional connectivity that is independent from anatomical proximity (Tononi and Edelman 1998). In addition, many scientists believe that there are multiple levels of consciousness (primary, secondary, and tertiary), and the sorts of processing associated with fear and pain are almost certainly associated with primary-process consciousness that are likely widespread among vertebrates (Panksepp 2005).

On the second point, the more we find out about the brain structure of fishes, the more we realise they effectively have analogous structures and functions to other vertebrates (Broglio et al. 2011; Demski 2013). The fish forebrain is dominated by eversion of pallial masses rather than evagination as in the other vertebrates, thus the topology is different which has hindered comparative studies. Nevertheless, over the last three decades, it has become evident that the teleost brain is in fact very similar to that of the rest of the vertebrates. For example, the teleost dorsal telencephalon represents the pallium and the ventral telencephalon is analogous to the subpallium and that these areas are highly connected to the rest of the brain (Rink and Wullimann 2004). The main divisions in the telencephalic dorsal pallium in fish are homologous to the tetrapod hippocampus, amygdala and neocortex (Broglio et al. 2011). We have known for a long time that areas of the telencephalon are involved in emotion, particularly the medium pallium, based on a data ranging from gene expression to behaviour. Similarly, the fish cerebellum is greatly involved in fear conditioning as it is in mammals (Sacchetti et al. 2009 for a review). Moreover, fMRI studies have shown that when suffering from pain, there is significant activity in the fish forebrain which is highly reminiscent of that observed in humans (see Sneddon 2011).

\section{Conclusions}

Fish have very good memories, live in complex social communities where they keep track of individuals and can learn from one another; a process that leads to the development of stable cultural traditions. They recognise themselves and others. They cooperate with one another and show signs of Machiavellian intelligence such as cooperation and reconciliation. They build complex structures, are 
capable of tool use and use the same methods for keeping track of quantities as we do. For the most part, their primary senses are just as good, and in many cases better, than our own. When comparing their behaviour to primates, one finds very few differences with the exception, perhaps, of the ability for imitation (Bshary et al. 2002). One must conclude, therefore, that the level of cognitive complexity displayed by fishes is on a par with most other vertebrates, and that if any animals are sentient then one must conclude that fish are too. While their brain evolutionary and developmental trajectory differs from other vertebrates, it is evident that there are many analogous structures that perform similar functions. This body of evidence strongly suggests that they are sentient and the evidence that they are capably of feeling pain in a manner similar to humans is gradually mounting. I submit that there are compelling reasons to include fish in our "moral circle" and afford them the protection they deserve.

\section{References}

Agrillo C, Piffer L, Bisazza A, Butterworth B (2012) Evidence for two numerical systems that are similar in humans and guppies. PLoS One 7(2):e31923

Agrillo C, Petrazzini MEM, Dadda M (2013) Illusionary patterns are fishy for fish, too. Front Neural Circuits 7:137

Amoser S, Ladich F (2005) Are hearing sensitivities of freshwater fish adapted to the ambient noise in their habitats? J Exp Biol 208:3533-3542

Antell SE, Keating DP (1983) Perception of numerical invariance in neonates. Child Dev 54:695-701

Appleby MC, Sandøe P (2002) Philosophical debate on the nature of well-being: implications for animal welfare. Anim Welf 11:283-294

Arnold KE (2000) Kin recognition in rainbowfish (Melanotaenia eachamensis): sex, sibs and shoaling. Behav Ecol Sociobiol 48:385-391

Aronson LR (1956) Further studies on orientation and jumping behavior in the goby fish, Bathygobius soporator. Anat Rec 125:606

Ashley PJ, Ringrose S, Edwards KL, Wallington E, McCrohan CR, Sneddon LU (2009) Effect of noxious stimulation upon antipredator responses and dominance status in rainbow trout. Anim Behav 77:403-410

Balda RP, Kamil AC (1992) Long-term spatial memory in clark's nutcracker, Nucifraga columbiana. Anim Behav 44:761-769

Barton RA, Venditti C (2013) Human frontal lobes are not relatively large. Proc Natl Acad Sci 110:90019006

Bekoff M (2006) Animal passions and beastly virtues: reflections on redecorating nature. Temple University Press, Philadelphia

Bekoff M, Sherman PW (2004) Reflections on animal selves. Trends Ecol Evol 19:176-180

Beukemaj JJ (1970) Acquired hook-avoidance in the pike Esox Lucius L. fished with artificial and natural baits. J Fish Biol 2:155-160

Bhat A, Magurran AE (2006) Benefits of familiarity persist after prolonged isolation in guppies. J Fish Biol 68:759-766

Bibost A-L, Brown C (2013) Laterality enhances schooling position in rainbowfish, Melaotaenia spp. PLoS One 8(11):e80907

Biebach H, Gordijn M, Krebs JR (1989) Time-and-place learning by garden warblers, Sylvia borin. Anim Behav 37:353-360

Bisazza A, Brown C (2011) Lateralization of cognitive functions in fish. In: Brown C, Krause J, Laland KN (eds) Fish cognition and behavior. Wiley, Oxford, pp 298-324 
Bisazza A, Cantalupo C, Capocchiano M, Vallortigara G (2000) Population lateralisation and social behaviour: a study with 16 species of fish. Laterality 5:269-284

Bitterman ME (1965) The evolution of intelligence. Sci Am 212:92-100

Bitterman ME (1975) The comparative analysis of learning. Science 188:699-709

Block N (1991) Evidence against epiphenomenonalism. Behav Brain Sci 14:670-672

Bonanni R, Natoli E, Cafazzo S, Valsecchi P (2011) Free-ranging dogs assess the quantity of opponents in intergroup conflicts. Anim Cogn 14:103-115

Bouton ME, Peck CA (1989) Context effects of conditioning, extinction, and reinstatement in an appetitive conditioning preparation. Anim Learn Behav 17:188-198

Braithwaite VAB, Huntingford FA (2004) Fish and welfare: do fish have the capacity for pain perception and suffering? Anim Welf 13:s87-s92

Broglio C, Gómez A, Durán E, Salas C, Rodríguez F (2011) Brain and cognition in teleost fish. In: Brown C, Krause J, Laland K (eds) Fish cognition and behavior. Wiley, Oxford, pp 325-358

Broom DM (2001) Evolution of pain. R Soc Med Int Congr Symp Ser 246:17-25

Brown C (2001) Familiarity with the test environment improves escape responses in the crimson spotted rainbowfish, Melanotaenia duboulayi. Anim Cogn 4:109-113

Brown C (2005) Cerebral lateralisation; social constraints and coordinated antipredator responses. Behav Brain Sci 28:591-592

Brown C (2012) Tool use in fishes. Fish Fish 13:105-115

Brown C, Bibost A-L (2014a) Laterality is linked to personality in the black-lined rainbowfish, Melanotaenia nigrans. Behav Ecol Sociobiol 68:999-1005

Brown C, Bibost L-A (2014b) Laterality influences cognitive performance in rainbowfish Melanotaenia duboulayi. Anim Cogn. doi:10.1007/s10071-014-0734-3

Brown C, Laland K (2002a) Social enhancement and social inhibition of foraging behaviour in hatcheryreared Atlantic salmon. J Fish Biol 61:987-998

Brown C, Laland KN (2002b) Social learning of a novel avoidance task in the guppy: conformity and social release. Anim Behav 64:41-47

Brown C, Laland K (2011) Social learning in fishes. In: Brown C, Krause J, Laland K (eds) Fish cognition and behavior. Wiley, Oxford, pp 240-257

Brown C, Warburton K (1999) Social mechanisms enhance escape responses in shoals of rainbowfish, Melanotaenia duboulayi. Environ Biol Fish 56:455-459

Brown C, Gardner C, Braithwaite VA (2004) Population variation in lateralised eye use in the poeciliid Brachyraphis episcopi. Proc R Soc Lond B 271:S455-S457

Brown C, Laland K, Krause J (2011a) Fish cognition and behavior. In: Brown C, Krause J, Laland K (eds) Fish cognition and behaviour. Wiley, Oxford, pp 1-9

Brown GE, Ferrari MCO, Chivers DP (2011b) Learning about danger: chemical alarm cues and threatsensitive assessment of predation risk by fishes. In: Brown C, Krause J, Laland K (eds) Fish cognition and behavior. Wiley, Oxford, pp 59-80

Bshary R (2011) Machiavellian intelligence in fishes. In: Brown C, Krause J, Laland K (eds) Fish cognition and behavior. Wiley, Cambridge, pp 277-297

Bshary R, Wurth M (2001) Cleaner fish Labroides dimidiatus manipulate client reef fish by providing tactile stimulation. Proc R Soc Lond B 268:1495-1501

Bshary R, Wickler W, Fricke H (2002) Fish cognition: a primate's eye view. Anim Cogn 5:1-13

Bshary R, Hohner A, Ait-el-Djoudi K, Fricke H (2006) Interspecific communicative and coordinated hunting between groupers and giant moray eels in the Red Sea. PLoS Biol 4:e431

Bshary R, Gingins S, Vail AL (2014) Social cognition in fish. Trends Cogn Sci. doi:10.1016/j.tics.2014.04.005

Byrne R, Whiten A (1989) Machiavellian intelligence II: Extensions and evaluations. Cambridge University Press 
Carpenter A (1887) Monkeys opening oysters. Nature 36:53

Chandroo KP, Yue S, Moccia RD (2004) An evaluation of current perspectives on consciousness and pain in fishes. Fish Fish 5:281-295

Cheng K, Newcombe NS (2005) Is there a geometric module for spatial orientation? Squaring theory and evidence. Psychon Bull Rev 12:1-23

Chivers DP, Brown GE, Smith RJF (1995) Familiarity and shoal cohesion in fathead minnows (Pimephales promelas)—implications for antipredator behavior. Can J Zool 73:955-960

Collett TS, Graham P (2004) Animal navigation: path integration, visual landmarks and cognitive maps. Curr Biol 14:R475-R477

Coussi-Korbel S (1994) Learning to outwit a competitor in mangabeys (Cercocebus torquatus torquatus). J Comp Psychol 108:164-171

Damasio A (1999) The feeling of what happens. Heinemann, London

Dawkins MS (1998) Evolution and animal welfare. Q Rev Biol 73:305-328

Dawkins MS (2001) Who needs consciousness? Anim Welf 10(Suppl 1):19-29

Demski LS (2013) The pallium and mind/behavior relationships in Teleost fishes. Brain Behav Evol 82:31-44

Deutschlander ME, Greaves DK, Haimberger T, Hawryshyn CW (2001) Functional mapping of UV photosensitivity during metamorphic transitions in a salmonid fish, Oncorhynchus mykiss. J Exp Biol 204:2401-2413

Dill LM (1977) Refraction and the spitting behavior of the archerfish (Toxotes chatareus). Behav Ecol Sociobiol 2:169-184

Dittman A, Quinn T (1996) Homing in Pacific salmon: mechanisms and ecological basis. J Exp Biol 199:83-91

Douglas R, Hawryshyn C (1990) Behavioural studies of fish vision: an analysis of visual capabilities. In: Douglas R, Djamgoz M (eds) The visual system of fish. Springer, Netherlands, pp 373-418

Dugatkin LA, Godin J-GJ (1992) Reversal of female mate choice by copying in the guppy Poecilia reticulata. Proc $\mathrm{R}$ Soc Lond B 249:179-184

Duncan IJH, Petherick JC (1991) The implications of cognitive processes for animal welfare. J Anim Sci 69:5017-5022

Fagan JF, Singer LT (1983) Infant recognition memory as a measure of intelligence. Adv Infancy Res 2:31-78

Ferno" A, Huse G, Jakobsen PJ, Kristiansen TS (2011) The role of fish learning skills in fisheries and aquaculture. In: Brown C, Krause J, Laland KN (eds) Fish cognition and behaviour. Blackwell, Oxford, pp 278-310

Fisher J, Hinde RA (1949) The opening of milk bottles by birds. Br Birds 42:347-358

Fricke H (1974) Öko-Ethologie des monogamen Anemonenfisches Amphiprion bicinctus. Z Tierpsychol 36:429-512

Frommen JG, Luz C, Bakker TCM (2007) Kin discrimination in sticklebacks is mediated by social learning rather than innate recognition. Ethology 113:276-282

Frostman P, Sherman PT (2004) Behavioral response to familiar and unfamiliar neighbors in a territorial cichlid, Neolamprologus pulcher. Ichthyol Res 51:283-285

Fuss T, Belackmann H, Schleussel $V(2014)$ The brain creates illusions not just for us: sharks (Chiloscyllium griseum) can "see the magic" as well. Front Neural Circuits 8:24

Gallup GG (1970) Chimpanzees: self recognition. Science 167:86-87

Gerlach G, Hodgins-Davis A, Avolio C, Schunter C (2008) Kin recognition in zebrafish: a 24-hour window for olfactory imprinting. Proc R Soc Lond B 275:2165-2170

Gomahr A, Palzenberger M, Kotrschal K (1992) Density and distribution of external taste buds in cyprinids. Environ Biol Fish 33:125-134 
Gómez-Laplaza L, Gerlai R (2011a) Can angelfish (Pterophyllum scalare) count? Discrimination between different shoal sizes follows Weber's law. Anim Cogn 14:1-9

Gómez-Laplaza L, Gerlai R (2011b) Spontaneous discrimination of small quantities: shoaling preferences in angelfish (Pterophyllum scalare). Anim Cogn 14:565-574

Gómez-Laplaza LM, Morgan E (2005) Time-place learning in the cichlid angelfish, Pterophyllum scalare. Behav Process 70:177-181

Griffiths SW, Magurran AE (1997) Familiarity in schooling fish; how long does it take to acquire. Anim Behav 53:945-949

Grutter AS, Rumney JG, Sinclair-Taylor T, Waldie P, Franklin CE (2011) Fish mucous cocoons: the 'mosquito nets' of the sea. Biol Lett 7:292-294

Hansell M, Ruxton GD (2008) Setting tool use within the context of animal construction behaviour. Trends Ecol Evol 23:73-78

Hara TJ (1994) Olfaction and gustation in fish: an overview. Acta Physiol Scand 152:207-217

Hawkins A, Amorim MC (2000) Spawning sounds of the male haddock, Melanogrammus aeglefinus. Environ Biol Fish 59:29-41

Helfman GS, Schultz ET (1984) Social transmission of behavioural traditions in a coral reef fish. Anim Behav 32:379-384

Hermer L, Spelke ES (1994) A geometric process for spatial reorientation in young children. Nature 370:57-59

Heyes CM (1993) Imitation, culture and cognition. Anim Behav 46:999-1010

Heyes CM (1994) Social learning in animals: categories and mechanisms. Biol Rev 69:207-231

Hogue ME, Beaugrand JP, Laguë PC (1996) Coherent use of information by hens observing their former dominant defeating or being defeated by a stranger. Behav Process 38:241-252

Hunt GR (1996) Manufacture and use of hook-tools by New Caledonian crows. Nature 379:249-251

Huntingford FA, Adams C, Braithwaite VA, Kadri S, Pottinger TG, Sandøe P, Turnbull JF (2006) Current issues in fish welfare. J Fish Biol 68:332-372

Irving E, Brown C (2013) Examining the link between personality and laterality in a feral guppy Poecilia reticulata population. J Fish Biol 83:311-325

Iwama GK (2007) The welfare of fish. Dis Aquat Org 75:155-158

Johnston CE, Johnson DL (2000) Sound production in Pimephales notatus (Rafinesque) (Cyprinidae). Copeia 2000:567-571

Jones AM, Brown C, Gardner S (2011) Tool use in the tuskfish Choerodon schoenleinii? Coral Reefs 30:865

Kamermans M, Hawryshyn CW (2011) Teleost polarisation vision: how it might work and what it might be good for. Philos Trans R Soc Lond B 366:742-756

Kandel ER, Schwartz JH, Jessell TM (2000) Principles of neural science. McGraw-Hill, New York

Kelley JL, Brown C (2011) Predation risk and decision making in poeciliid prey. In: Evans JP, Pilastro A, Schlupp I (eds) Ecology and evolution of poeciliid fishes. University of Chicago Press, pp 174184

Kelley JL, Magurran AE (2003) Learned predator recognition and anti-predator responses in fishes. Fish Fish 4:216-226

Kirkwood KK, Hubrecht R (2001) Animal consciousness, cognition and welfare. Anim Welf 10(Supplement 1):5-17 Kitchen DM (2004) Alpha male black howler monkey responses to loud calls: effect of numeric odds, male companion behavior and reproductive investment. Anim Behav 67:125-139

Klausewitz W (1960) Ein bemerkenswerter Zähmungsversuch an freilebenden Fischen. Natur Volk 90:91-96

Kydd E, Brown C (2009) Loss of shoaling preference for familiar individuals in captive-reared crimson spotted rainbowfish Melanotaenia duboulayi. J Fish Biol 74:2187-2195 
Lachlan RF, Crooks L, Laland KN (1998) Who follows whom? Shoaling preferences and social learning of foraging information in guppies. Anim Behav 56:181-190

Laland K, Williams K (1997) Shoaling generates social learning of foraging information in guppies. Anim Behav 53:1161-1169

Lefebvre L, Nicolakakis N, Boire D (2002) Tools and brains in birds. Behavior 139:939-973

Lund V, Mejdell CM, Rocklingsberg H, Anthony R, Hastein T (2007) Expanding the moral circle: farmed fish as objects of moral concern. Dis Aquat Org 75:109-118

Macphail EM (1998) The evolution of consciousness. Oxford University Press, Oxford

Magurran AE, Seghers BH, Shaw PW, Carvalho GR (1994) Schooling preferences for familiar fish in the guppy, Poecilia reticulata. J Fish Biol 45:401-406

McComb K, Packer C, Pusey A (1994) Roaring and numerical assessment in contests between groups of female lions, Panthera leo. Anim Behav 47:379-387

Mcphail EM (1982) Brian and intelligence in vertebrates. Oxford University Press, Oxford

Means LW, Ginn SR, Arolfo MP, Pence JD (2000) Breakfast in the nook and dinner in the dining room: time-of-day discrimination in rats. Behav Process 49:21-33

Miklósi Á , Topál J, Csányi V (2004) Comparative social cognition: what can dogs teach us? Anim Behav 67:995-1004

Milinski M (1990) On cooperation in sticklebacks. Anim Behav 40:1190-1191

Milinski M (2003) The function of mate choice in sticklebacks: optimizing MHC genetics. J Fish Biol 63:116

Mouritsen H, Ritz T (2005) Magnetoreception and its use in bird navigation. Curr Opin Neurobiol 15:406414

Nelson A, Alemadi S, Wisenden B (2013) Learned recognition of novel predator odour by convict cichlid embryos. Behav Ecol Sociobiol 67:1269-1273

Neumeyer C (1982) Wavelength discrimination in the goldfish. J Comp Phys A 171:639-649

Nicol CJ (1996) Farm animal cognition. Anim Sci 62:375-391

Nieder A, Dehaene S (2009) Representation of number in the brain. Ann Rev Neurosci 32:185-208

Odling-Smee L, Braithwaite VA (2003) The role of learning in fish orientation. Fish Fish 4:235-246

Oliveira RF, McGregor PK, Latruffe C (1998) Know thine enemy: fighting fish gather information from observing conspecific interactions. Proc R Soc Lond B 265:1045-1049

Östlund-Nilsson S, Holmlund M (2003) The artistic three-spined stickleback (Gasterosteous aculeatus). Behav Ecol Sociobiol 53:214-220

Oulton LJ, Haviland V, Brown C (2013) Predator recognition in rainbowfish, Melanotaenia duboulayi, embryos. PLoS One 8(10):e76061

Panksepp J (2005) Affective consciousness: core emotional feelings in animals and humans. Conscious Cogn 14:30-80

Parker ST, Mitchell RW, Boccia ML (1994) Self-awareness in animals and humans: developmental perspectives. Cambridge University Press, New York

Pavlov IP (1927) Conditioned reflexes. Oxford University Press, Oxford

Popper AN, Lu Z (2000) Structure-function relationships in fish otolith organs. Fish Res 46:15-25

Proops L, McComb K (2012) Cross-modal individual recognition in domestic horses (Equus caballus) extends to familiar humans. Proc R Soc Lond B 279:3131-3138

Reader S (2003) Innovation and social learning: individual variation and brain evolution. Anim Biol 53:147-158

Reader SM, Laland KN (2002) Social intelligence, innovation and enhanced brain size in primates. Proc Natl Acad Sci 99:4436-4441

Reebs S (1996) Time-place learning in golden shiners (Pisces: Cyprinidae). Behav Process 36:253-262

Reebs S (1999) Time-place learning based on food but not on predation risk in a fish, the inanga (Galaxias maculatus). Ethology 105:361-371 
Reilly SC, Quinn JP, Cossins AR, Sneddon LU (2008) Behavioural analysis of a nociceptive event in fish: comparisons between three species demonstrate specific responses. Appl Anim Behav Sci 114:248-259

Reiss D, Marino L (2001) Mirror self-recognition in the bottlenose dolphin: a case of cognitive convergence. Proc Natl Acad Sci 98:5937-5942

Rink E, Wullimann MF (2004) Connections of the ventral telencephalon (subpallium) in the zebrafish (Danio rerio). Brain Res 1011:206-220

Rogers LJ (2002) Lateralization in vertebrates: its early evolution, general pattern, and development. Adv Study Behav 31:107-161

Rollin BE (1989) The unheeded cry: animal consciousness animal pain and science. Oxford University Press, Oxford, UK

Romanes GJ (1882) Animal intelligence. Appleton and Co., New York

Rose JD (2002) The neurobehavioral nature of fishes and the question of awareness and pain. Rev Fish Sci 10:1-38

Rose JD, Arlinghaus R, Cooke SJ, Diggles BK, Sawynok W, Stevens ED, Wynne CDL (2014) Can fish really feel pain? Fish Fish 15:97-133

Rosenthal G (1999) Using video playback to study sexual communication. Environ Biol Fish 56:307-316

Rosenthal GG, Evans CS (1998) Female preference for swords in Xiphophorus helleri reflects a bias for large apparent size. Proc Natl Acad Sci 95:4431-4436

Roth G, Dicke U (2005) Evolution of the brain and intelligence. Trends Cogn Sci 9:250-257

Rugani R, Fontanari L, Simoni E, Regolin L, Vallortigara G (2009) Arithmetic in newborn chicks. Proc R Soc Lond B 276:2451-2460

Sacchetti B, Scelfo B, Strata P (2009) Cerebellum and emotional behaviour. Neuroscience 162:756-762

Seed A, Byrne R (2010) Animal tool-use. Curr Biol 20:R1032-R1039 Shettleworth, SJ (2010) Cognition, evolution, and behaviour, 2nd edn. Kindle Edition. Oxford University Press, Oxford

Siebeck UE, Parker AN, Prenger D, Mathger LM, Wallis G (2010) Covert face recognition in a species of reef fish. Curr Biol 20:407-410

Silk JB (1999) Male bonnet macaques use information about third-party rank relationships to recruit allies. Anim Behav 58:45-51

Simpson SD, Meekan MG, McCauley RD, Jeffs A (2004) Attraction of settlement-stage coral reed fishes to reef noise. Mar Ecol Prog Ser 276:263-268

Skinner BF (1938) The behavior of organisms: an experimental analysis. Appleton-Century-Crofts, New York

Sneddon LU (2003) The evidence for pain in fish: the use of morphine as an analgesic. Appl Anim Behav Sci 83:153-162

Sneddon LU (2011) Pain perception in fish: evidence and implications for the use of fish. J Conscious Stud 18:209-229

Sneddon LU (2013) Cognition and welfare. In: Brown C, Krause J, Laland K (eds) Fish cognition and behaviour. Wiley, Cambridge, pp 405-434

Sneddon LU, Braithwaite VA, Gentle MJ (2003) Novel object test: examining nociception and fear in the rainbow trout. J Pain 4:431-440

Solomon RL, Wynne LC (1954) Traumatic avoidance learning: the principles of anxiety conservation and partial irreversibility. Psychol Rev 61:353-385

Sovrano VA (2004) Visual lateralization in response to familiar and unfamiliar stimuli in fish. Behav Brain Res 152:385-391

Sovrano VA, Bisazza A (2008) Recognition of partly occluded objects by fish. Anim Cogn 11:161-166

Sovrano VA, Bisazza A (2009) Perception of subjective contours in fish. Perception 38:579-590 
Sovrano VA, Bisazza A, Vallortigara G (2002) Modularity and spatial reorientation in a simple mind: encoding of geometric and nongeometric properties of a spatial environment by fish. Cognition 85:B51-B59

Sovrano VA, Bisazza A, Vallortigara G (2003) Modularity as a fish (Xenotoca eiseni) views it: conjoining geometric and nongeometric information for spatial reorientation. J Exp Psychol Anim Behav Process 29:199-210

Stevens JR, Cushman FA, Hauser MD (2005) Evolving the psychological mechanisms for cooperation. Ann Rev Ecol Evol Syst 36:499-518

Sulkowski GM, Hauser MD (2001) Can rhesus monkeys spontaneously subtract? Cognition 79:239-262

Taborsky M (1984) Broodcare helpers in the cichlid fish, Lamprologus brichardi: their costs and benefits. Anim Behav 32:1236-1252

Tebbich S, Bshary R, Grutter A (2002) Cleaner fish Labroides dimidiatus recognise familiar clients. Anim Cogn 5:139-145

Thornhill R, Gangestad SW, Miller R, Scheyd G, McCollough JK, Franklin M (2003) Major histocompatibility complex genes, symmetry, and body scent attractiveness in men and women. Behav Ecol 14:668-678

Thorpe WH (1956) Learning and instinct in animals. Methuen, London

Thünken T, Waltschyk N, Bakker T, Kullmann H (2009) Olfactory self-recognition in a cichlid fish. Anim Cogn 12:717-724

Tolman EC (1948) Cognitive maps in rats and men. Psychol Rev 55:189-208

Tononi G, Edelman G (1998) Consciousness and complexity. Science 282:1846-1851

Trick LM, Pylyshyn ZW (1994) Why are small and large numbers enumerated differently: a limitedcapacity preattentive stage in vision. Psychol Rev 101:80-102

Vallortigara G, Rogers LJ (2005) Survival with an asymmetrical brain: advantages and disadvantages of cerebral lateralization. Behav Brain Sci 28:575-633

Vallortigara G, Chiandetti C, Sovrano VA (2011) Brain symmetry (animal). Wiley Interdiscip Rev Cogn Sci 2:146-157

van Lawick-Goodall J (1970) Tool-using primates and other vertebrates. In: Lehrman D, Hinde R, Shaw E (eds) Advances in the study of behavior, vol 3. Academic Press, New York, pp 195-249

Vargas JP, López JC, Salas C, Thinus-Blanc C (2004) Encoding of geometric and featural spatial information by goldfish (Carassius auratus). J Comp Psychol 118(2):206-216

von Frisch K (1913) Weitere Untersuchungen über den Farbensinn der Fische. Zool Jahrb Abt allg Zool Physiol Tiere 34:43-68

von Frisch K (1941) Über einen Schreckstoff der Fischhaut und seine biologische Bedeutung. Z vergl Physiol 29:46-145

Walker MM, Diebel CE, Haugh CV, Pankhurst PM, Montgomery JC, Green CR (1997) Structure and function of the vertebrate magnetic sense. Nature 390:371-376

Whalen J, Gallistel CR, Gelman R (1999) Nonverbal counting in humans: the psychophysics of number representation. Psychol Sci 10:130-137

White G, Brown C (2013) Site fidelity and homing behaviour in intertidal fishes. Mar Biol 160:1365-1372

Whiten A, Byrne RW (1997) Machiavellian intelligence II: extensions and evaluations. Cambridge University Press, Cambridge

Wynn K (1992) Addition and subtraction by human infants. Nature 358:749-750

Wyzisk K, Neumeyer C (2007) Perception of illusory surfaces and contours in goldfish. Vis Neurosci 24:291-298

Yamamoto S, Humle T, Tanaka M (2013) Basis for cumulative cultural evolution in chimpanzees: social learning of a more efficient tool-use technique. PLoS One 8(1):e55768 